\title{
Coroplast investiert 35 Mio. Euro
}

Coroplast tätigt die größte zusammenhängende Investition in der 85-jährigen Firmengeschichte. Das Wuppertaler Unternehmen erstellt derzeit ein neues Gebäude und schafft damit Platz für ein Hochregallager sowie zusätzliche Produktionsbzw. Arbeitsflächen.

$A_{s}^{u}$ uf dem Gelände des Coroplast tammwerkes in Wuppertal-Nächstebreck entsteht zurzeit ein Neubau mit über $9.000 \mathrm{~m}^{2}$ Nutzfläche. Notwendig wurde das Großprojekt durch die erhebliche Steigerung des Umsatzes von Coroplast in den vergangenen drei Jahren: „Dieser konnte mehr als verdoppelt werden“, begründet Marcus Söhngen, Geschäftsführer und Leiter des Geschäftsbereiches Technische Klebebänder die millionenschwere Investition. Die neue Halle 12 wird Platz für ein Hochregallager sowie zusätzliche Produktionsbzw. Arbeitsfläche für Vertriebs- und
Entwicklungsstellen schaffen. Neue Maschinen zur Herstellung von Klebebändern sind bereits bestellt; die Installation soll bereits im Juni beginnen. Das Unternehmen rechnet derzeit mit der Inbetriebnahme aller Gebäudebereiche im Laufe des kommenden Oktobers. Das projektierte Gebäude und bereits bestellte Maschinen stehen in der ersten Stufe für eine Investitionssumme von 25 Mio. €. Weitere 10 Mio. € hält Coroplast für zukünftig notwendig werdende Ergänzungen bereit. Am Stammsitz Wuppertal werden Klebebänder und elektrische Leitungen hergestellt; aktu-

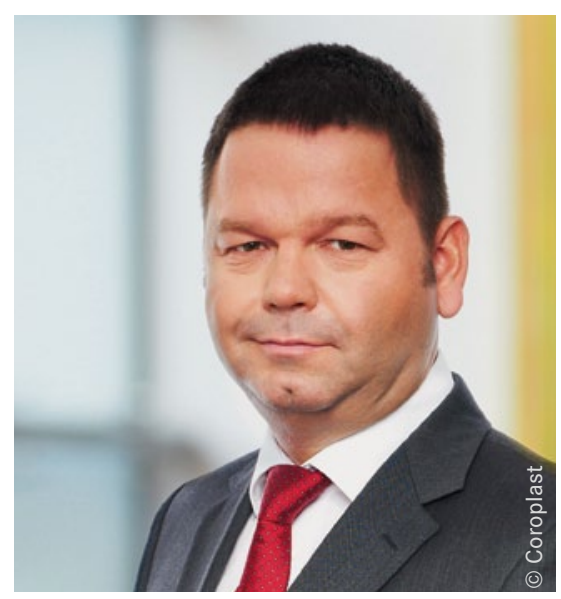

Marcus Söhngen, Geschäftsführer von Coroplast:,Wir haben in unserem Geschäftsbereich Klebebänder seit 2010 den Umsatz mehr als verdoppelt. Die Investition in Gebäude und Produktionskapazität war dringend erforderlich, um den Standort Nächstebreck fit zu machen für die Zukunft.“

ell arbeiten hier etwa 700 Menschen. „Wir bekommen mit dem neuen Gebäude ebenso die Möglichkeit, logistische Abläufe zu verbessern und durch die räumliche Zusammenführung von Vertrieb und Entwicklung ein Kompetenzzentrum für Klebebänder einzurichten. So schaffen wir auch die räumlichen Voraussetzungen für die Einstellung neuer Mitarbeiter“, so Söhngen.

3D-Simulation des derzeit entstehenden Neubaus

\section{Veranstaltungen Juni}

\begin{tabular}{|l|l|l|l|}
\hline Termin & Ort & Thema & Veranstalter \\
\hline 05.06.2013 & Nürnberg & Kleben im Automobilbau & $\begin{array}{l}\text { Bayern Innovativ } \\
\text { Tel: 0911 20671-0 } \\
\text { www.bayern-innovativ.de/veranstaltungen }\end{array}$ \\
\hline 11.-13.06.2013 & Frankfurt/M. & techtextil & $\begin{array}{l}\text { Messe Frankfurt } \\
\text { Tel: }+49697575-0 \\
\text { www.techtextil.messefrankfurt.com }\end{array}$ \\
\hline 11.-12.06.2013 & Stade & 7. CFK-Valley Stade Convention & $\begin{array}{l}\text { CFK-Valley Stade Convention GbR } \\
\text { Tel: +49 4141 40740-22 } \\
\text { www.cfk-convention.com }\end{array}$ \\
\hline 18.- 19.06.2013 & Bremen & $\begin{array}{l}\text { IFAM } \\
\text { Tel: }+49 \text { 421 2246-566 } \\
\text { www.ifam.fraunhofer.de }\end{array}$ \\
\hline
\end{tabular}

